\title{
3 Research Suare \\ Outcomes in Pulmonary Sarcoidosis: Results of a Newly Implemented Prednisone Protocol.
}

\section{Nynke A. Kampstra ( $\square$ nynkekampstra@gmail.com )}

RIVM: Rijksinstituut voor Volksgezondheid en Milieu https://orcid.org/0000-0001-8789-3291

\section{Philip J. van der Wees}

Radboudumc IQ healthcare

\section{Frouke T. van Beek}

Saint Antonius: Sint Antonius Ziekenhuis

\section{Douwe H. Biesma}

LUMC: Leids Universitair Medisch Centrum

\section{Jan C. Grutters}

Saint Antonius: Sint Antonius Ziekenhuis

\section{Paul B. van der Nat}

Saint Antonius: Sint Antonius Ziekenhuis

\section{Research}

Keywords: Quality improvement, Healthcare quality improvement, Implementation science, Sarcoidosis.

Posted Date: May 4th, 2021

DOl: https://doi.org/10.21203/rs.3.rs-423129/v1

License: (c) (1) This work is licensed under a Creative Commons Attribution 4.0 International License. Read Full License 


\section{Abstract \\ Background}

Prednisone is used as first-line therapy for patients with pulmonary sarcoidosis. There is however no clear association between prednisone dose and FVC change in patients with pulmonary sarcoidosis. In order to improve our standard of care we introduced a more conservative prednisone protocol.

\section{Methods}

This study is a single centre observational non-inferiority study. In the new protocol, prednisone intake was reduced from a starting dose of $40 \mathrm{mg}$ to a starting dose of $20 \mathrm{mg}$ and was introduced on the $1 \mathrm{st}$ of September 2017. Primary outcomes evaluated were FVC \% predicted, FEV1 \% predicted and DLCO \% predicted. The secondary outcome measure was BMI.

\section{Results}

369 patients were included in the old-cohort (Sept. 2015 - Sept. 2017) and 215 in the new-cohort (Oct. 2017 - Sept. 2019). In the old-cohort, 182 (49.0\%) of the patients were treated with prednisone. In total, 114 patients $(62.6 \%)$ were treated according to the old protocol with a mean initial prednisone dose of $32.1 \pm 14.2 \mathrm{mg}$. In the new-cohort, 93 patients (45.0\%) were treated with prednisone of which 53 patients $(57.0 \%)$ received prednisone according to the new protocol. The mean initial prednisone dose in the newcohort was $21.4 \pm 9.8 \mathrm{mg}$. Changes in FVC and FEV1 \% predicted did not vary. Change in \% predicted DLCO was $2.4 \pm 9.3$ for the old-cohort and $-1.3 \pm 11.4$ for the new-cohort $(p=0.01)$. No statistically significant changes in BMI were observed.

\section{Conclusions}

Our results indicate that in more than half of the patients the new protocol was followed. The new protocol with reduced prednisone intake seems non-inferior compared to the old prednisone protocol looking at the changes in pulmonary function and BMI. We have shown that applying VBHC principles in a sarcoidosis centre can promote the delivery of high-value clinical care.

\section{Contributions To The Literature}

- A more conservative prednisone regimen for patients with pulmonary sarcoidosis might be equally effective. The initial prednisone dose was changed to $20 \mathrm{mg}$ (coming from $40 \mathrm{mg}$ ). In addition, a consequent lower prednisone dose throughout the treatment was advised and indications to start therapy were changed. 
- We have shown that applying value-based healthcare (VBHC) principles in a sarcoidosis center can promote the delivery of high-value clinical care.

- Our findings can be used by other health care organizations to maximize the success of VBHC in increasing and improving the implementation of an evidence-based clinical practice.

\section{Background}

Previously, a standard set for measuring and comparing outcomes over time was developed for patients with pulmonary sarcoidosis.[1] Furthermore, the set has been evaluated on its feasibility and to assess whether changes in outcomes between centres were observed.[2] In the literature, several standard sets have been developed applying value-based healthcare (VBHC).[3-6] One of the aims of VBHC is to measure clinical outcomes relevant for a specific patient group divided by the costs.[7] However, efforts in applying these sets and the actual use of clinical outcomes to identify quality improvement (QI) initiatives are lacking.[8]

Sarcoidosis is a multisystem disease which is histologically characterized by granulomatous inflammations. [9] In $90 \%$ of the cases the lungs are affected. The first-line therapy option for patients with pulmonary sarcoidosis remains prednisone.[9-11] The aim of therapy should be the prevention of inflammation and further deterioration of any organ damage and improving the quality of life, while avoiding negative side-effects such as weight gain.[12-14] Although prednisone treatment in patients with pulmonary sarcoidosis is reported to induce short-term benefits concerning the inflammation level, the balance between dosage level and adverse side effects remains unclear.[11] Evidence for the most optimal prednisone treatment regimen is lacking. Protocols vary both nationally and internationally in prednisone dosage and tapering schemes. The suggested initial prednisone dose varies between $20-40$ mg.[9]

A study evaluating what dosing strategy has the best balance between effect on pulmonary function and side-effects showed there was no clear association between prednisone dose and FVC change in newlytreated patients with pulmonary sarcoidosis.[15] Weight gain on the other hand was correlated with cumulative prednisone dose. Long-term and high-dose prednisone therapy is associated with a large number of side-effects impacting patients' quality of life, such as weight gain, diabetes, mood swings and osteoporosis.[14, 16] Given the adverse effects of corticosteroids and the lack of studies evaluating the most optimal dosage regimen, it is advised to lower patients' initial prednisone dose and realize faster tapering. $[14,15]$ However, it is unknown how this new regimen impacts patients' pulmonary function test (PFT) results and BMI. Therefore, we aimed to evaluate the effectiveness of a newly developed prednisone protocol which was implemented in September 2017 at the St. Antonius hospital. We looked at how the new prednisone doses scheme affected patients' pulmonary function and weight over time.

\section{Methods}




\subsection{Context and study design}

This study is a single centre observational non-inferiority study, performed at the St. Antonius hospital in Nieuwegein, the Netherlands. The protocol for prednisone treatment was selected as an intervention after seven team meetings by the quality improvement team. In Table 1 more information is provided what was discussed during the meetings. This quality improvement team consisted of five team members including pulmonologists $(n=2)$ and researchers $(n=3)$. The final decision of the intervention was discussed with a specialized nurse from the interstitial lung disease (ILD) unit. After the intervention was selected, this was presented to the team of ILD nurses and one dietician. In Table 1, a full timeline is provided of the implementation process. We evaluated the implementation process of the QI by comparing this with the steps as described by the Implementation of Change Model (ICM).[17] The ICM has been used successfully in the process of implementing improvement initiatives.[18] 
Table 1

Implementation process and steps by the Implementation of Change Model (ICM).

\section{Step of the Date Description of the process Implementation of Change Model}

1. Development of proposal for change
December

2016 -

May 2017
Based on outcome data of the standard set developed for pulmonary sarcoidosis patients, 7 meetings of 1 hour were organized with the quality improvement team in order to critically look at the data. The quality improvement team consisted of two pulmonologists, two senior researchers and one PhD student. Based on insights from 6 centres and 509 patients, baseline BMI values differed between centres. Specifically for our own centre we have looked at the patients with long term prednisone use ( $\geq 2$ years) and the change of BMI over time. We found that these patients had a higher $\mathrm{BMI}$ and that their $\mathrm{BMI}$ increased more compared to patients using prednisone for a shorter time, which is also known from the literature. As weight gain is experienced as a burden for patients, we wanted to minimize this and wanted to impact the patients weight changes over time.

$\begin{array}{ll}\text { 2. Analysis of } & \text { December } \\ \text { actual } & 2016- \\ \text { performance, } & \text { May } 2017 \\ \text { targets for } & \\ \text { change } & \end{array}$

2. Analysis of performance, change

We analysed the following data:

1) Mortality

2) Changes in pulmonary function (forced vital capacity (FVC), forced expiratory volume in $1 \mathrm{~s}$, diffusing capacity of the lung for carbon monoxide)

3) Soluble interleukin-2 receptor (sIL-2R) change

4) Weight changes

5) Quality-of-life (QoL) measures

6) Osteoporosis

7) Clinical outcome status (COS)

In addition we have looked at prednisone use for only the St. Antonius hospital. Our targets for change were prednisone dosage and BMI change.

3. Problem analysis of target group and setting

4. Development and selection of strategies and measures to change practice
June 2017

- August

2017

August

2017 -

September 2019
We organized a meeting with a specialized nurse to present data and the rationale for the after protocol. A presentation was given to nurses, dieticians after protocol and get their input.
An email was sent to all pulmonologists and residents with the information when the new protocol would be launched. A pulmonologist from the quality improvement team made sure that during the multi-disciplinary team meeting, the protocol would be guiding the treatment choices. 


\begin{tabular}{l}
$\begin{array}{l}\text { Step of the Date Description of the process } \\
\text { Implementation } \\
\text { of Change } \\
\text { Model }\end{array}$ \\
\hline
\end{tabular}

\section{5.}

Development, testing and execution of implementation plan

$\begin{array}{ll}\text { 6. Integration } & 1 \text { st of } \\ \text { of changes in } & \text { September } \\ \text { routine care } & 2017\end{array}$

May 2017

- August

2017

We developed the implementation plan. The quality improvement team was involved as well a nurse from the ILD unit. In the implementation plan we explained the rationale, objectives implementation actions and the analysis plan. The implementation plan was presented to the ILD nurses by the PhD student.

No pilot phase was integrated as this concerned the change of a protocol for prednisone treatment for routine care. An email was sent to all pulmonologists and residents with the information of the new prednisone protocol and the date was announced when the protocol would be active. A pulmonologist from the quality improvement team made sure that during the multidisciplinary team meetings the protocol would be used as guidance for the treatment of patients with pulmonary sarcoidosis.
The protocol was evaluated 2 years after the protocol was implemented, as this time span would have sufficient number of patients in order to look at the effect on outcomes (pulmonary function, $\mathrm{BMI}$ and initial prednisone dose). No adjustments were made in the protocol after this was launched on September 1st 2017.

Steps of the ICM adapted from Grol \& Wensing (2013)[26]

\subsection{Quality improvement process}

During the quality improvement process, the outcome data of the earlier developed standard set for patients with pulmonary sarcoidosis were discussed.[1,2] During the seven meetings with the quality improvement team, the plan-do-study-act (PDSA) method was used as a tool to guide the process.[19] During the meetings, we discussed the outcome data and went through the following three questions: What do we want to accomplish? What outcomes do we wish to improve? What changes can we make that can potentially lead to an improvement?[19]

One of the quality improvement team members facilitated and prepared the presentations and meetings. After each session, additional data analyses were needed until we reached consensus concerning the final quality improvement initiative.

\subsection{Prednisone protocol}

The new prednisone protocol was active since the first of September 2017. The old scheme was reevaluated after insights from the literature and previous outcomes.[15] Differences between the old and new protocol were the initial prednisone dose of $40 \mathrm{mg}$ and $20 \mathrm{mg}$, respectively. In addition, a consequent lower prednisone dose throughout the treatment was advised in the new protocol (Table 2). As for the old and new protocol, the protocol is used as guidance and allows for deviation. In the new protocol, it was advised that patients would not start on prednisone when: 1) patients had a $\mathrm{BMI} \geq 25$; 2) patients were 
diagnosed with diabetes mellitus; 3) patients were known with pseudo-resistant hypertension or 4) when patients were diagnosed with osteoporosis. Reasons to stop prednisone therapy would be: 1) limited response to prednisone (persistent activity); 2 ) weight gain of $>5 \%$ of initial weight before the patient started with prednisone; 3 ) the patient developed steroid-induced DM/hypertension or osteoporosis or 4) due to other side-effects (e.g. insomnia, mood swings, etc.).

Table 2

Doses regimen prednisone.

\begin{tabular}{|ll|}
\hline Old doses regimen & New doses regimen \\
\hline$\cdot 4$ weeks $40 \mathrm{mg} /$ day & $\cdot 3$ weeks $20 \mathrm{mg} /$ day \\
\hline$\cdot 4$ weeks $30 \mathrm{mg} /$ day & $\cdot 3$ weeks $17,5 \mathrm{mg} /$ day \\
\hline$\cdot 4$ weeks $20 \mathrm{mg} /$ day & $\cdot 3$ weeks $15 \mathrm{mg} /$ day \\
\hline$\cdot-2,5 \mathrm{mg}$ per4 weeks until maintenance dose of $10 \mathrm{mg} /$ day & $\cdot 3$ weeks $12,5 \mathrm{mg} /$ day \\
\hline & $\cdot$ Maintenance dose of $10 \mathrm{mg} /$ day \\
\hline
\end{tabular}

If it concerned a patient who was being referred to us and prednisone was started elsewhere (often higher dosage), the information of the therapy starting at our clinic was used. If e.g. a referral patient was switched to 2 nd and/or 3rd line therapy or a tapering scheme was initiated by the pulmonologist, the patient was considered as being treated according to the (new) protocol.

\subsection{Measures and outcomes}

For this study the main outcome measures were pulmonary function test (PFT) results and weight change over time. Specifically, we aimed to observe whether changes in forced vital capacity (FVC) \% predicted, forced expiratory volume in 1 second (FEV1) \% predicted, diffusing capacity of the lung for carbon monoxide (DLCO) \% predicted and weight occurred after the new protocol was initiated. Secondly, we wanted to compare the mean initial dosage of prednisone before and after the initiation of the protocol. Also, we aimed to study in how many patients the protocol was being followed when receiving treatment with prednisone. Medical records were reviewed for diagnostic data, demographics, weight, pulmonary function parameters, and initial prednisone dose. The rationale for a non-inferiority study design was based on the expectation that non-inferiority of the clinical effect of the new protocol would be sufficient from a clinical perspective. The non-inferiority margin for \% predicted FVC, FEV1 and DLCO was defined as when there was more than a $10 \%$ worsening in PFT compared to the before-cohort. All patients provided informed consent as part of the overall biobank policy. This is a broader informed consent form where patients agree their medical data and biobank material are being used for scientific purposes.

\subsection{Patient and public involvement}

Patients and the public were not involved in the design of the study. During a research meeting, data and the idea to adjust the prednisone protocol was presented to a patient representative. The patient did not 
comment on the manuscript.

\subsection{Statistical analysis}

The comparison of means of continuous variables was tested with the student t-test. Next, a MannWhitney $\mathrm{U}$ test or Chi-square test was performed. FVC, $\mathrm{FEV} 1$ and $\mathrm{DLCO}_{\mathrm{C}}$ is shown as mean percent (\%) predicted ( \pm standard deviation (SD)) or as mean absolute change of \% predicted ( \pm SD) compared to baseline. All pulmonary function results are based on the European Community for Steel and Coal reference equations.[20]

Weight is shown as mean $\mathrm{kg}( \pm \mathrm{SD})$ or as mean absolute change $( \pm S D)$ in $\mathrm{kg}$ compared to baseline. Prednisone dose is shown as mean daily dose in mg. All analyses were performed in SPSS (IBM SPSS Statistics version 24). A p-value of $<0.05$ was considered statistically significant.

\section{Results}

\subsection{Description of the cohorts}

A total of 369 patients were included in the old-cohort and 215 patients in the new-cohort. First mean \% predicted FVC was $96.9 \pm 19.5$ in the old-cohort and $98.3 \pm 18.8$ in the new-cohort. First mean \% predicted FEV1 was $88.5 \pm 21.1$ in the old-cohort and $89.0 \pm 20.4$ in the new-cohort. Mean \% predicted DLCO was $74.8 \pm 16.2$ for the old-cohort and $77.9 \pm 18.7(p=0.01)$ for the new-cohort (Table 3$)$. Average body mass index (BMI) was $27.6 \pm 5.6 \mathrm{~kg} / \mathrm{m} 2$ in the old-cohort and $27.9 \pm 6.0 \mathrm{~kg} / \mathrm{m} 2$ in the new-cohort. In the oldcohort $58.3 \%$ were men, in the new-cohort $53.5 \%$ were men. The mean change between the first and last $\%$ predicted FVC and FEV1 improved in both cohorts. The mean change of \% predicted FVC and DLCO was significantly different between the two cohorts. Additional characteristics are shown in Table 3 . 
Table 3

Characteristics of old-cohort versus new-cohort.

\begin{tabular}{|c|c|c|c|}
\hline & Old-cohort & New-cohort & p-value $\S$ \\
\hline & $\mathrm{n}=369$ & $\mathrm{n}=\mathbf{2 1 5}$ & \\
\hline Gender & & & \\
\hline Male $(\mathrm{n},(\%))$ & $215(58.3)$ & $115(53.5)$ & 0.35 \\
\hline Female (n, (\%)) & $150(40.7)$ & $99(46.0)$ & \\
\hline Age (mean, (sd)) & $49 \pm 12.2$ & $51 \pm 13.0$ & 0.09 \\
\hline BMl at first PFT (kg/m2) & $28.2 \pm 5.5$ & $28.0 \pm 5.7$ & 0.47 \\
\hline Weight at first PFT & $86.5 \pm 17.7$ & $84.9 \pm 18.7$ & 0.19 \\
\hline Treated with prednisone (n, (\%)) & $182(49.3)$ & $93(43.7)$ & 0.18 \\
\hline Mean first PFT (mean, (sd)) & & & \\
\hline$\%$ predicted FVC & $96.9 \pm 19.5$ & $98.3 \pm 18.8$ & 0.19 \\
\hline \% predicted FEV1 & $88.5 \pm 21.1$ & $89.0 \pm 20.4$ & 0.64 \\
\hline$\%$ predicted DLCO & $74.8 \pm 16.2$ & $77.9 \pm 18.7$ & 0.03 \\
\hline Mean change (mean, (sd)) $\Omega$ & & & \\
\hline$\%$ predicted FVC & $1.9 \pm 9.4$ & $0.9 \pm 9.9$ & 0.04 \\
\hline$\%$ predicted FEV1 & $0.9 \pm 9.3$ & $0.3 \pm 10.1$ & 0.60 \\
\hline$\%$ predicted DLCO & $2.3 \pm 8.5$ & $-0.5 \pm 9.7$ & 0.00 \\
\hline$\S \mathrm{p}$-values were calculated with & $\mathrm{y} \cup$ test or $\mathrm{Ch}$ & e test. & \\
\hline $\begin{array}{l}\Omega \text { Number of months between } 1 \mathrm{~s} \\
\text { (cohort 2017-2019). }\end{array}$ & vas $23.1 \pm 1$ & ort 2015-20 & $16.0 \pm 13.6$ \\
\hline $\begin{array}{l}\text { Abbreviations. DLCOc: diffusing } \\
\text { levels), PFT: pulmonary function, } \\
\text { second, kg: kilograms, mg: millig }\end{array}$ & $\begin{array}{l}\text { g for carbon } \\
\text { tal capacity, }\end{array}$ & $\begin{array}{l}\text { ide (correctec } \\
\text { orced expirat }\end{array}$ & $\begin{array}{l}\text { moglobin } \\
\text { ume in } 1\end{array}$ \\
\hline
\end{tabular}

\subsection{Patients treated with prednisone}

In the old-cohort, $182(49.3 \%)$ patients needed treatment with prednisone. In the new-cohort, 93 (43.7\%) patients needed treatment with prednisone. The mean initial prednisone dose in the old-cohort was 32.1 $\pm 14.2 \mathrm{mg}$. Mean initial prednisone dose in the new-cohort was significantly lower, $21.4 \pm 9.8 \mathrm{mg}(\mathrm{p}<$ 0.001). In the old-cohort, $62.6 \%$ of the patients started on $\leq 40 \mathrm{mg}$ prednisone. In the new-cohort $57.0 \%$ of the patients started with prednisone according to the new protocol, i.e. on $\leq 20 \mathrm{mg}$ prednisone. For some patients the explanation why their initial prednisone dose was higher than the protocol was provided by a 
pulmonologist (Table 4). In many patients the dose was higher when it concerned patients coming from a referral centre. So before entering our cohort, the patients already started on a higher prednisone dose in another hospital. When arriving at our hospital, the 13 patients described in Table 4 were all put on prednisone tapering schemes and/or second-line therapy was introduced. 
Table 4

Overview of patients with higher initial prednisone dose.

\begin{tabular}{|c|c|c|}
\hline Patient & $\begin{array}{l}\text { Treated } \\
\text { according } \\
\text { to } \\
\text { protocol }\end{array}$ & Short therapy overview by pulmonologist \\
\hline 1 & Yes & $\begin{array}{l}\text { Rightly treated according to protocol here. At first visit to our hospital } \\
\text { prednisone already reduced by referral hospital to } 10 \mathrm{mg} \text { (started elsewhere } \\
\text { before referral to us at } 60 \mathrm{mg} \text { ). Steroid-saving MTX included. }\end{array}$ \\
\hline 2 & Yes & $\begin{array}{l}\text { On first visit } 20 \mathrm{mg} \text { prednisone. Started with } 60 \mathrm{mg} \text { elsewhere. Then reduced } \\
\text { by } 2.5 \mathrm{mg} \text { per month from } 6-2018 \text { to maintenance of } 10 \mathrm{mg} \text {. }\end{array}$ \\
\hline 3 & Yes & $\begin{array}{l}\text { On first visit } 20 \mathrm{mg} \text { prednisone. Elsewhere started with } 60 \mathrm{mg} \text {. Started steroid- } \\
\text { sparing after MTX evaluation. Reduction here also slightly slower }(2.5 \mathrm{mg} \text { per } \\
4 \text { weeks instead of every } 3 \text { weeks. }\end{array}$ \\
\hline 4 & Yes & $\begin{array}{l}\text { Started with } 60 \mathrm{mg} \text { prednisone due to renal sarcoidosis elsewhere in May } \\
\text { 2018. Hereafter MTX was started and prednisolone was reduced. }\end{array}$ \\
\hline 5 & No & $\begin{array}{l}\text { Started with prednisone } 60 \mathrm{mg} \text { elsewhere Sept } 2017 \text { due to cardiac } \\
\text { sarcoidosis. Nov } 2017 \text { first seen here with still } 60 \mathrm{mg} \text { prednisone. MTX } \\
\text { (steroid-sparing) started immediately on our first visit, however this had to be } \\
\text { discontinued due to hepatic MTX-toxicity. Therefore, prednisone was } \\
\text { continued in quite a high dose with Azathioprine as a steroid-sparing therapy. } \\
\text { So here due to circumstances and severity of cardiac sarcoidosis, a higher } \\
\text { dose of prednisone was deliberately chosen for a longer period of time. }\end{array}$ \\
\hline 6 & Yes & $\begin{array}{l}\text { Started with } 40 \mathrm{mg} \text { prednisone elsewhere. After referral to our hospital, MTX } \\
\text { was started as steroid-sparing therapy and prednisone was tapered off (in } 8 \\
\text { weeks to } 10 \mathrm{mg} \text { ). }\end{array}$ \\
\hline 7 & Yes & $\begin{array}{l}\text { Started with } 40 \mathrm{mg} \text { prednisone elsewhere. After referral to our hospital steroid- } \\
\text { sparing therapy with MTX and tapering of prednisone was started (adjusted } \\
\text { tapering schedule, but in } 3 \text { months to } 10 \mathrm{mg} \text { maintenance). }\end{array}$ \\
\hline 8 & Yes & $\begin{array}{l}\text { Came in with } 10 \mathrm{mg} \text { of prednisone from elsewhere. MTX steroid-sparing } \\
\text { therapy (BMI 28) and prednisone tapering was started in our hospital } \\
\text { immediately. }\end{array}$ \\
\hline 9 & Yes & $\begin{array}{l}\text { Started prednisone elsewhere, starting dose unknown. When getting in, } 15 \mathrm{mg} \\
\text { prednisone was taken. Elsewhere also started MTX from a steroid-saving } \\
\text { point of view. At our centre prednisone was directly further reduced to } 10 \mathrm{mg} \\
\text { maintenance }\end{array}$ \\
\hline 10 & Yes & $\begin{array}{l}\text { Came in with } 20 \mathrm{mg} \text { of prednisone, which was started elsewhere. Starting } \\
\text { dose elsewhere: } 40 \mathrm{mg} 2 \text { days later immediately } 20 \mathrm{mg} \text {. Immediately reduced } \\
\text { here (per } 2 \text { weeks instead of per } 3 \text { weeks) due to BMI of } 39 \text {. MTX built up } \\
\text { immediately also from a steroid-sparing point of view. }\end{array}$ \\
\hline 11 & Yes & $\begin{array}{l}\text { Entering from elsewhere with } 10 \mathrm{mg} \text { prednisone and } 15 \mathrm{mg} \text { MTX (from a } \\
\text { steroid-sparing point of view). Prednisone immediately decreased to } 0 \mathrm{mg} \\
\text { ( } 2.5 \mathrm{mg} \text { per } 4 \text { weeks) under plaquenil which was started with the purpose of } \\
\text { also decreasing the MTX and providing plaquenil as monotherapy. }\end{array}$ \\
\hline
\end{tabular}

Abbreviations. BMI: body mass index, MTX: methotrexate. 


\begin{tabular}{|lll|}
\hline Patient & $\begin{array}{l}\text { Treated } \\
\text { according } \\
\text { to } \\
\text { protocol }\end{array}$ & Short therapy overview by pulmonologist \\
\hline 12 & Yes & $\begin{array}{l}\text { Came in with } 10 \mathrm{mg} \text { prednisone. Elsewhere started with } 40 \mathrm{mg} \text {. Started with } \\
\text { steroid-sparing MTX at our centre and prednisone was tapered (tapering } \\
\text { schedule } 2.5 \mathrm{mg} \text { every } 4 \text { weeks). }\end{array}$ \\
\hline 13 & Yes & $\begin{array}{l}\text { Came in with } 5 \text { mg prednisone from elsewhere and had methylprednisolone } \\
\text { at our centre in July 2018 due to severe cardiac sarcoidosis. Afterwards, MTX } \\
\text { was started as steroid-sparing therapy due previous weight gain with } \\
\text { prednisone. }\end{array}$ \\
\hline Abbreviations: BMl: body mass index, MTX: methotrexate.
\end{tabular}

\subsubsection{Pulmonary function}

First mean \% predicted FVC was $94.6 \pm 19.8$ in the old-cohort and $94.1 \pm 22.0$ in the new-cohort. First mean \% predicted FEV1 was $84.8 \pm 22.0$ in the old-cohort and $84.5 \pm 22.6$ in the new-cohort. Mean \% predicted DLCO was $73.2 \pm 16.5$ for the old-cohort and $74.8 \pm 21.4$ for the new-cohort (Table 5). 
Table 5

Characteristics of patients on prednisone old-cohort versus the new-cohort.

\begin{tabular}{|c|c|c|c|}
\hline & $\begin{array}{l}\text { Old-cohort } n= \\
182\end{array}$ & $\begin{array}{l}\text { New-cohort } n= \\
93\end{array}$ & $\begin{array}{l}\text { p-value } \\
\S\end{array}$ \\
\hline \multicolumn{4}{|l|}{ Gender } \\
\hline Male $(\mathrm{n},(\%))$ & $109(60.2)$ & $50(53.8)$ & 0.46 \\
\hline Female (n, (\%)) & $72(39.8)$ & $43(46.2)$ & \\
\hline Age (mean, (sd)) & $48 \pm 12.2$ & $50 \pm 12.8$ & 0.18 \\
\hline $\begin{array}{l}\text { Mean prednisone dose at start in mg (mean, } \\
\text { (sd)) }\end{array}$ & $32.1 \pm 14.2$ & $21.4 \pm 9.8$ & 0.00 \\
\hline BMI at first PFT (mean, (sd)) & $27.6 \pm 5.6$ & $27.9 \pm 6.0$ & 0.86 \\
\hline Weight at first PFT (mean, (sd)) & $84.8 \pm 17.5$ & $84.5 \pm 18.7$ & 0.74 \\
\hline \multicolumn{4}{|l|}{ Treated according to protocol (n, (\%)) } \\
\hline Yes, \% & $114(62.6)$ & $53(57.0)$ & 0.01 \\
\hline \multicolumn{4}{|l|}{ Mean initial prednisone dose (n, (\%)) } \\
\hline$>10 \leq 20 \mathrm{mg}$ & $45(24.7)$ & $49(52.7)$ & 0.00 \\
\hline$>21 \leq 30 \mathrm{mg}$ & $42(23.1)$ & $16(17.2)$ & \\
\hline$>31 \leq 40 \mathrm{mg}$ & $27(14.8)$ & $6(6.5)$ & \\
\hline$>41 \leq 50 \mathrm{mg}$ & $1(0.5)$ & $2(2.2)$ & \\
\hline$>51 \leq 60 \mathrm{mg}$ & $15(8.2)$ & $1(1.1)$ & \\
\hline$>61 \mathrm{mg}$ & $2(1.1)$ & 0 & \\
\hline Initial dose missing, $\%$ & $50(27.5)$ & $19(20.4)$ & \\
\hline \multicolumn{4}{|l|}{ Mean first PFT (mean, (sd)) } \\
\hline$\%$ predicted FVC & $94.6 \pm 19.8$ & $94.1 \pm 22.0$ & 0.95 \\
\hline$\%$ predicted FEV1 & $84.8 \pm 22.0$ & $84.5 \pm 22.6$ & 0.87 \\
\hline$\%$ predicted DLCO & $73.2 \pm 16.5$ & $74.8 \pm 21.4$ & 0.82 \\
\hline
\end{tabular}

$\S p$-values were calculated with a Mann-Whitney U test or Chi-square test.

$\Omega$ Number of months between 1 st and last PFT was $24.1 \pm 15.3$ (cohort 2015-2017) and $12.3 \pm 11.4$ (cohort 2017-2019).

Abbreviations: DLCOc: diffusing capacity of lung for carbon monoxide (corrected for hemoglobin levels), PFT: pulmonary function, FVC: forced vital capacity, FEV1: forced expiratory volume in 1 second, kg: kilograms, mg: milligrams, m: meter. 


\begin{tabular}{|c|c|c|c|}
\hline & $\begin{array}{l}\text { Old-cohort } n= \\
182\end{array}$ & $\begin{array}{l}\text { New-cohort } n= \\
93\end{array}$ & $\begin{array}{l}\text { p-value } \\
\S\end{array}$ \\
\hline \multicolumn{4}{|c|}{ Mean change (mean, (sd)) $\Omega$} \\
\hline$\%$ predicted FVC & $2.6 \pm 10.2$ & $2.0 \pm 9.4$ & 0.25 \\
\hline$\%$ predicted FEV1 & $1.1 \pm 10.3$ & $1.5 \pm 9.3$ & 0.89 \\
\hline$\%$ predicted DLCO & $2.4 \pm 9.3$ & $-1.3 \pm 11.4$ & 0.01 \\
\hline \multicolumn{4}{|c|}{$\S p$-values were calculated with a Mann-Whitney U test or Chi-square test. } \\
\hline \multicolumn{4}{|c|}{$\begin{array}{l}\Omega \text { Number of months between } 1 \text { st and last PFT was } 24.1 \pm 15.3 \text { (cohort 2015-2017) and } 12.3 \pm 11.4 \\
\text { (cohort 2017-2019). }\end{array}$} \\
\hline \multicolumn{4}{|c|}{$\begin{array}{l}\text { Abbreviations. DLCOc: diffusing capacity of lung for carbon monoxide (corrected for hemoglobin } \\
\text { levels), PFT: pulmonary function, FVC: forced vital capacity, FEV1: forced expiratory volume in } 1 \\
\text { second, kg: kilograms, mg: milligrams, m: meter. }\end{array}$} \\
\hline
\end{tabular}

Average body mass index (BMI) was $27.6 \pm 5.6 \mathrm{~kg} / \mathrm{m} 2$ in the old-cohort and $27.9 \pm 6.0 \mathrm{~kg} / \mathrm{m} 2$ in the newcohort. The mean change between the first and last \% predicted FVC and FEV1 improved in both cohorts. The mean change of \% predicted DLCO was significantly different between the two cohorts with $2.4 \pm 9.3$ increase and $1.3 \pm 11.4$ decrease in the old-cohort and new-cohort, respectively. This difference was not clinically relevant. Additional baseline characteristics are presented in Table 5.

\subsubsection{BMI}

First BMI measured for patients treated with prednisone in the old $(n=182)$ and new $(n=97)$ cohort did not differ between the cohorts, which was $27.6 \pm 5.6$ for the old and $27.9 \pm 6.0$ for the new-cohort. The second measured BMI was $27.5 \pm 5.5$ for the old and $28.1 \pm 6.0$ for the new-cohort. In Table 6, BMI measured at different time points is given for patients being treated with prednisone. BMI did not significantly differ at any point in time between the patients from the old and new-cohort. 
Table 6

BMI of patients treated with prednisone in the 2015-2017 versus the 2017-2019 cohort.

\begin{tabular}{|c|c|c|c|}
\hline & Old-cohort & New-cohort & P-value \\
\hline $\mathrm{BMI}$ at $1 \mathrm{st}^{\mathrm{d}} \mathrm{PFT}$ (mean, (sd)) & $27.6 \pm 5.6$ & $27.9 \pm 5.9$ & 0.63 \\
\hline Number of patients & $\mathrm{n}=182$ & $\mathrm{n}=97$ & \\
\hline BMI at 2rd PFT (mean, (sd)) & $27.5 \pm 5.5$ & $28.1 \pm 6.0$ & 0.40 \\
\hline Number of patients & $\mathrm{n}=182$ & $\mathrm{n}=97$ & \\
\hline Number of months between 1 st and 2nd PFT & $24.1 \pm 15.3$ & $12.3 \pm 11.4$ & \\
\hline BMI at 3rd PFT (mean, (sd)) & $27.2 \pm 5.3$ & $27.9 \pm 6.0$ & 0.46 \\
\hline Number of patients & $n=157$ & $\mathrm{n}=50$ & \\
\hline Number of months between 1 st and 3rd PFT & $26.5 \pm 14.8$ & $16.7 \pm 11.2$ & \\
\hline $\mathrm{BMI}$ at 4th PFT (mean, (sd)) & $28.0 \pm 5.4$ & $27.5 \pm 7.1$ & 0.62 \\
\hline Number of patients & $\mathrm{n}=132$ & $\mathrm{n}=36$ & \\
\hline Number of months between 1 st and 4 th PFT & $28.8 \pm 14.6$ & $19.3 \pm 12.0$ & \\
\hline BMI at 5th PFT (mean, (sd)) & $27.0 \pm 4.7$ & $26.9 \pm 3.7$ & 0.95 \\
\hline Number of patients & $n=105$ & $\mathrm{n}=14$ & \\
\hline Number of months between 1 st and 5th PFT & $31 \pm 15.2$ & $29.3 \pm 14.2$ & \\
\hline \multicolumn{4}{|c|}{ Continuous data are presented as mean \pm standard deviation. } \\
\hline
\end{tabular}

\section{Discussion}

In this study we observed unchanged clinical outcome data after implementing a more conservative prednisone protocol in our sarcoidosis centre. Specifically, the mean initial prednisone dose in the oldcohort was $32.1 \pm 14.2 \mathrm{mg}$ and in the new-cohort $21.4 \pm 9.8 \mathrm{mg}$. Comparing the old- and new-cohort, BMI did not significantly differ at any point in time, and change in \% predicted FVC and FEV1 did not vary between the groups. These data suggest that a more conservative prednisone treatment has the potential to be equally effective in treating patients with pulmonary sarcoidosis. Change in \% predicted DLCO was significantly different between the two groups. However, this difference was not clinically relevant.

The data of this study indicated that many referral patients from other clinics came in with a high dose of prednisone. Despite their high dose, these patients were treated following the new prednisone protocol in our centre. Some did not meet the new start criteria (BMI > 25, DM, hypertension or osteoporosis) beforehand or met the new stop criteria. Often, prednisone was being phased out and/or a treatment 
indication for second-line treatment was started. This was the case in all 13 patients from whom therapy decisions were described in more detail. In addition, in one case due to circumstances and severity of (cardiac) sarcoidosis, pulmonologists needed to deviate from the protocol. Thus, for referral patients we have managed to lower the burden due to prednisone therapy.

A retrospective study from The Netherlands consisting of 54 patients with pulmonary sarcoidosis concluded there was no clear association between prednisone dose and FVC change in newly-treated patients with pulmonary sarcoidosis.[15] Weight gain on the other hand was correlated with cumulative prednisone dose. Therefore, the authors concluded that prednisone treatment with a lower cumulative dose in the long term has the potential to be equally effective in treating patients with pulmonary sarcoidosis versus treatment with a higher dose strategy. Furthermore, lower dose prednisone treatment can reduce side-effects such as weigh gain, mood swings and the development of diabetes.[14] Due to the adverse effects of prednisone and the lack of knowledge concerning the most optimal balance between dose and side-effects, lower (initial) dose and faster tapering seem to be equally effective.[14, 15] Although a more detailed analysis would be needed to conclude this, it seems that from what is known from the literature in combination with our analysis, the new protocol is equally effective.

As this quality of sarcoidosis care improvement initiative was part of a value-based healthcare (VBHC) program, the new protocol was evaluated using data from daily clinical practice in combination with data from the literature. As reported elsewhere, despite the increasing interest in research on how to apply and translate knowledge into daily clinical practice and improve healthcare, the scientific knowledge in this field is slow.[21] Therefore rigorous evaluation of outcomes should remain part of research programs[21], also for future quality improvement initiatives for patients with pulmonary sarcoidosis.

The structure of realizing the QI project was shaped making use of the PDSA cycle. This made it possible to have structure and support during the meetings and in the process of defining the QI initiative, which was also acknowledged by others.[22]

A limitation of this study is that we performed a before-after analysis. This study design does not control for bias that might have occurred at the same time.[23] Therefore, it remains difficult to determine whether the protocol change itself was responsible for the observed non-inferior effect. Bias could have been that pulmonologists were already more conservative with prescribing prednisone before the new protocol was introduced based on insights from the literature. Also it would have been useful to study and evaluate the mean cumulative prednisone dosage over time and compare this to weight and BMI, which was done by other authors as well.[15] By doing this, it would be possible to draw more rigorous conclusions on the effect of the new dosage scheme. We were unable to collect detailed information concerning the cumulative dosage retrospectively. It was hard to get detailed trustworthy data in retrospect.

Another limitation is that we did not provide regular (e.g. monthly) updates on how many patients started on prednisone and what their initial dosage was. This concerns step seven of the ICM model, providing continuous evaluation and feedback on the number of patients being treated with prednisone and their 
respective dosage scheme. It would have been useful to discuss the data of the number of patients starting on prednisone and their respective dosage after the implementation of the new protocol with the pulmonologists and the nurses from the ILD department.

As stated elsewhere, claims made from improvements are sometimes far stronger than is warranted.[23, 24] We therefore suggest that our results can be used as a proof of concept, but we do suggest that the most optimal balance between prednisone dose, pulmonary function and side-effects should be studied in further detail. This can also be done as part of a prospective QI project, where the cumulative dosage of prednisone is also being monitored prospectively.

The continued work of measuring and comparing outcomes will allow to discuss best practices and challenges in a multicentre setting. When there is constant monitoring of health outcomes, this may have positive effects on outcomes. In a VBHC pilot study among IBD patients, positive trends such as fewer ED visits, fewer hospitalization and less long-term corticosteroid use were observed.[25] When consistently monitoring outcomes in care delivered for patients with sarcoidosis, this can empower participating centres to implement and monitor QI efforts throughout the cycle of care.

\section{Conclusions}

In summary, our study shows that VBHC principles can be applied in a sarcoidosis centre. Furthermore, the collected outcome data support the observation that a more conservative prednisone regimen might be equally effective. Future research should however perform a more rigorous assessment of the clinical effectiveness of the different regimens on radiological improvement, extrathoracic disease improvement and quality of life.

\section{Declarations}

\section{Ethics approval and consent to participate}

No ethical approval was needed, as it concerned a change in routine daily clinical care. All patients provided informed consent as part of the overall biobank policy. This is a broader informed consent form where patients agree their medical data and biobank material are being used for scientific purposes.

\section{Consent for publication}

Not applicable.

\section{Availability of data and materials}

The datasets used and/or analyzed during the current study are available from the corresponding author on reasonable request.

\section{Competing interests}


Prof. dr. Grutters reports grants from ZonMw, during the conduct of the study.

\section{Funding}

This work was supported by The Netherlands Organisation for Health Research and Development (ZonMw) under project number 842001005 . The funders had no role in the study design, data collection, analysis and decision in where to publish the manuscript.

\section{Authors' contributions}

PndN, PvdW and NK contributed to the design of the study, data analysis and interpretation. NK contributed to data analysis and interpretation and drafted the manuscript. NK extracted the data. NK conducted the statistical analyses. NK, PvdN, PvdW, FvB, JG and DB critically discussed the data contributed to the interpretation of results. PvdN, PvdW, FvB, JG and DB reviewed the manuscript. All authors read and approved the final manuscript.

\section{Acknowledgements}

We thank the sarcoidosis patient association (SBN) for the research grant awarded in 2016 for this project.

\section{Reporting Standards}

This paper and study design does not comply with the available pre-specified checklists.

\section{References}

1. Kampstra NA, Grutters JC, van Beek FT, et al. First patient-centred set of outcomes for pulmonary sarcoidosis: a multicentre initiative. BMJ open Respir Res. 2019;6:e000394.

2. Kampstra NA, van der Nat PB, Dijksman LM, van Beek FT, Culver DA, Baughman RP, ... \& Wijsenbeek MS. Results of the standard set for pulmonary sarcoidosis: feasibility and multicentre outcomes. ERJ Open Res 2019;5.

3. Daeter EJ, Timmermans MJC, Hirsch A, et al. Defining and Measuring a Standard Set of PatientRelevant Outcomes in Coronary Artery Disease. Am J Cardiol 2018.

4. Kim AH, Roberts C, Feagan BG, et al. Developing a standard set of patient-centred outcomes for inflammatory bowel disease-an international, cross-disciplinary consensus. J Crohn's Colitis. 2017;12:408-18.

5. Michelotti M, de Korne DF, Weizer JS, et al. Mapping standard ophthalmic outcome sets to metrics currently reported in eight eye hospitals. BMC Ophthalmol. 2017;17:269.

6. Morgans AK, van Bommel ACM, Stowell C, et al. Development of a standardized set of patientcentered outcomes for advanced prostate cancer: an international effort for a unified approach. Eur Urol. 2015;68:891-8. 
7. Porter ME. What is value in health care? N Engl J Med. 2010;363:2477-81.

8. Van Veghel D, Daeter EJ, Bax M, et al. Organization of outcome-based quality improvement in Dutch heart centres. Eur Hear Journal-Quality Care Clin Outcomes 2019.

9. Costabel U, Hunninghake GW, Committee SS. ATS/ERS/WASOG statement on sarcoidosis. Eur Respir J. 1999;14:735-7.

10. Schutt AC, Bullington WM, Judson MA. Pharmacotherapy for pulmonary sarcoidosis: a Delphi consensus study. Respir Med. 2010;104:717-23.

11. Paramothayan NS, Lasserson TJ, Jones P. Corticosteroids for pulmonary sarcoidosis. Cochrane Libr 2005.

12. Wijsenbeek MS, Culver DA. Treatment of sarcoidosis. Clin Chest Med. 2015;36:751-67.

13. Baughman RP, Costabel U, du Bois RM. Treatment of sarcoidosis. Clin Chest Med. 2008;29:533-48.

14. Grunewald J, Grutters JC, Arkema EV, et al. Publisher Correction: Sarcoidosis. Nat Rev Prim. 2019;5:49-019-0107-y.

15. Broos CE, Poell LHC, Looman CWN, et al. No evidence found for an association between prednisone dose and FVC change in newly-treated pulmonary sarcoidosis. Respir Med 2017.

16. Baughman RP, Drent M, Culver DA. Endpoints for clinical trials of sarcoidosis. Sarcoidosis Vasc Diffus lung Dis. 2012;29:90-8.

17. Grol R, Wensing M, Eccles $\mathrm{M}$, et al. Improving patient care; the implementation of change in health care. 2013.

18. Zipfel N, Van Der Nat PB, Rensing BJWM, et al. The implementation of change model adds value to value-based healthcare: A qualitative study. BMC Health Serv Res Published Online First: 2019.

19. Deming WE. Out of the Crisis: Quality, Productivity and Competitive Position. Massachusetts Inst Technol Cent Adv Eng study Published Online First: 1986.

20. Quanjer PH, Tammeling GJ, Cotes JE, et al. Lung volumes and forced ventilatory flows. Report Working Party Standardization of Lung Function Tests, European Community for Steel and Coal. Official Statement of the European Respiratory Society. Eur. Respir. J. Suppl. 1993.

21. Wensing M, Grol R. Knowledge translation in health: How implementation science could contribute more. BMC Med. 2019.

22. Peterson A, Gudbjornsdottir S, Lofgren UB, et al. Collaboratively Improving Diabetes Care in Sweden Using a National Quality Register: Successes and Challenges-A Case Study. Qual Manag Health Care. 2015;24:212-21.

23. Portela MC, Pronovost PJ, Woodcock T, et al. How to study improvement interventions: A brief overview of possible study types. BMJ Qual. Saf. 2015.

24. Benn J, Burnett S, Parand A, et al. Studying large-scale programmes to improve patient safety in whole care systems: Challenges for research. Soc Sci Med Published Online First. 2009. doi:10.1016/j.socscimed.2009.09.051. 
25. van Deen WK, Spiro A, Burak Ozbay A, et al. The impact of value-based healthcare for inflammatory bowel diseases on healthcare utilization: a pilot study. Eur J Gastroenterol Hepatol. 2017;29:331-7.

26. Grol R, Wensing M. Effective implementation of change in healthcare: A systematic approach. Improv Patient Care Implement Chang Heal care 2013;:40-63. 